11 Dion GL, Tohen M, Anthony WA, Waternaux CS. Symptoms and functioning of patients with bipolar disorder six months after hospitalization. Hosp Community Psychiatry 1998; 39: 652-7.

12 Harrow M, Goldberg JF, Grossman LS, Meltzer HY. Outcome in manic disorders. A naturalistic follow-up study. Arch Gen Psychiatry 1990; 47: 665-71.

13 Barkow K, Maier W, Ustun TB, Gansicke M, Wittchen HU, Heun R. Risk factors for depression at 12-month follow-up in adult primary health care patients with major depression: an international prospective study. J Affect Disord 2003; 76: 157-69.

14 Van Dongen CJ. Quality of life and self-esteem in working and nonworking persons with mental illness. Community Ment Health $J$ 1996; 32: 535-48

15 Nordt C, Muller B, Rossler W, Lauber C. Predictors and course of vocational status, income, and quality of life in people with severe mental illness: a naturalistic study. Soc Sci Med 2007; 65: 1420-9.

16 Mueser K, Salyers M, Mueser P. A prospective analysis of work in schizophrenia. Schizophr Bull 2001; 27: 281-96.

17 Wewiorski N, Fabian E. Association between demographic and diagnostic factors and employment outcomes for people with psychiatric disabilities: a synthesis of recent research. Ment Health Serv Res 2004; 6: 9-21.

18 Goldberg RW, Lucksted A, McNary S, Gold JM, Dixon L, Lehman A Correlates of long-term unemployment among inner-city adults with serious and persistent mental illness. Psychiatr Serv 2001; 52: 101-3.

19 Endicott J, Spitzer RL, Fleiss JL, Cohen J. The Global Assessment Scale. A procedure for measuring overall severity of psychiatric disturbance. Arch Gen Psychiatry 1976; 33: 766-71.

20 World Health Organization Division of Mental Health. SCAN Schedules for Clinical Assessment in Neuropsychiatry, Version 1.0. WHO, 1992.

21 Burke-Miller JK, Cook JA, Grey DD, Razzano LA, Blyler CR, Leff HS, et al. Demographic characteristics and employment among people with severe mental illness in a multisite study. Community Ment Health J 2006; 42: 143-59.

22 Wykes T, Reeder C, Landau S, Everitt B, Knapp M, Patel A, et al. Cognitive remediation therapy in schizophrenia. Randomised controlled trial. Br J Psychiatry 2007; 190: 421-7.

23 Burns T, Catty J, Becker T, Drake RE, Fioritti A, Knapp M, et al. The effectiveness of supported employment for people with severe mental illness: a randomised controlled trial. Lancet 2007; 370: 1146-52.

\title{
Controlled comparison of two crisis resolution and home treatment teams
}

\author{
P. Tyrer, ${ }^{1}$ F. Gordon, ${ }^{1}$ S. Nourmand, ${ }^{1}$ M. Lawrence, ${ }^{2}$ C. Curran, ${ }^{2}$ D. Southgate, ${ }^{3}$ B. Oruganti, ${ }^{4}$
} M. Tyler, ${ }^{5}$ S. Tottle, ${ }^{5}$ B. North, ${ }^{1}$ E. Kulinskaya, ${ }^{1}$ J. T. Kaleekal, ${ }^{4}$ J. Morgan ${ }^{2}$

The Psychiatrist (2010), 34, 50-54, doi: 10.1192/pb.bp.108.023077

${ }^{1}$ Imperial College London; ${ }^{2}$ Pendine Centre, Cardiff; ${ }^{3}$ Whitchurch Hospital, Cardiff; ${ }^{4}$ South Cardiff Crisis Resolution and Home Treatment Team; ${ }^{5}$ Cardiff and Vale NHS Trust

Correspondence to Peter Tyrer (p.tyrer@imperial.ac.uk)
Aims and method To compare an existing crisis resolution service with a new crisis resolution team (CRT) in Wales. The impact of the new team was measured by changes in bed days and admissions. A random sample of patients from each service was assessed for service satisfaction, social functioning and quality of life after first presentation.

Results The total number of bed days was reduced following the introduction of the new CRT (27.3\%). The frequency and duration of compulsory admissions increased by $31 \%$ in the CRT between the first and second years and by $7 \%$ in the control service, offset by a greater reduction in informal admissions in the CRT (23.5\%) compared with the control group (13.3\%); overall bed usage was unchanged. Service satisfaction, social functioning and quality of life showed no important differences between the services.

Clinical implications Crisis resolution teams may reduce informal admissions in the short term but at the cost of more compulsory admissions later.

Declaration of interest None.
The notion of crisis resolution has been known for over 50 years but only recently has been integrated into general service strategies. It was first introduced and developed by Caplan, ${ }^{1}$ whose influence has perhaps not been sufficiently acknowledged in the recent development of crisis resolution services for a different population, people with severe mental illness. The introduction of these teams nationally has been an attempt to reduce the number of hospital admissions and is now part of UK government policy., ${ }^{2,3}$ Despite this, the evidence for the effectiveness of the crisis resolution teams (CRTs) is relatively limited and only one randomised controlled trial has been carried out. ${ }^{4}$ Nevertheless, it is fair to say that earlier studies ${ }^{5-7}$ were also controlled and used similar methods as current CRTs. The 
trial by Johnson et $a l^{4}$ showed that a CRT significantly reduced admissions compared with a control group both in the short and medium term but had no impact on compulsory admissions. In the recent national survey in the UK, areas with established crisis resolution and home treatment teams were shown to have a $10 \%$ reduction in admissions compared with areas without such teams, although the total duration of bed usage was only reduced by $5 \% .^{8,9}$ In view of the relatively limited evidence base for the effectiveness of CRTs, we carried out a comparative study in Wales at the time a new crisis resolution team was introduced.

\section{Method}

The chosen method was an ecological case control. In April 2005, Cardiff psychiatric services opened a new CRT service in the centre of Cardiff. This was the first urban crisis resolution and home treatment team in Wales, but shortly after it had been set up and before it could be evaluated fully, the decision was made to extend it to the rest of Cardiff and thus the second team began its work in June 2006. The teams' catchment areas were different in size and socioeconomic circumstances. The central area covered by the first crisis team had a population of 86622 and was in a less affluent part of the city. The larger area, which included the western suburbs with Cardiff Vale, had a population of 214 393. To compare these two areas, we recorded data for two 9-month periods in both areas: between 1 June 2004 and 28 February 2005 and then between 1 June 2005 and 29 February 2006 (the similar time scales allowed for seasonal variation).

The members of the CRT were trained by one of the longest established services in the UK in Birmingham ${ }^{10}$ and followed the standard model of this service. The team had full gatekeeping function so that all admissions had to be approved by it, and at least one member of the team was involved in every assessment for admission, including Mental Health Act assessments. The service was staffed for 24-hour cover.

The study had three aims.

1 To compare the total length of stay per patient, total number of bed days, number of hospital admissions and admission status (informal or compulsory) in the area covered by the new team (CRT) and that covered by the existing services (control) for two 9-month periods before and after the introduction of the new team.

2 To compare the data on service user satisfaction, social functioning and quality of life in those referred to the CRT and those referred to the control service, by questionnaires collected from a random sample of patients from both services.

3 To compare the number of suicides in the areas covered by the two services before and after the introduction of the CRT.

This information was collected by two methods. Admission data routinely collected by the services were separated into CRT and control groups by:

- total number of admissions

- total bed occupancy
- admissions and bed occupancy by mental health status (compulsory $v$. informal)

- number of admissions per patient and length of stay for each admission.

The data on social functioning and service satisfaction were obtained from a random sample of service users approximately 4 weeks after assessment for admission in both areas. These questionnaires were given by staff working in the area and the randomised lists were prepared (by S.N.) independently.

\section{Analysis}

It is now well established that psychiatric in-patient admissions are distributed in an exponential curve, with most patients staying a short time and a few staying for a very long time. ${ }^{11}$ We therefore logarithmically transformed the data measuring bed days so that the parametric statistics could be used in making comparison between groups. The Huffman test ${ }^{12}$ was used to compare the number of admissions for groups separated by age and mental health status, and the Welch $t$-test ${ }^{13}$ was used to compare means between the two catchment areas. Hierarchical linear models were used for the analysis of the total length of stay per patient (added over all admissions for a patient) with patients, general practice surgeries and type of service as the three levels in the hierarchy; $\mathrm{R}$ statistical language ${ }^{14}$ and STATA program gllamm ${ }^{15}$ were used.

We assumed that the population of the two areas did not change significantly over the 2 years of the study.

For the service user component of the study, a random sample of 138 patients taken from those referred for assessment for admission in both groups was approached 1 month after first admission or crisis contact and requested to complete questionnaires for service user satisfaction, ${ }^{16}$ social functioning ${ }^{17}$ and quality of life. ${ }^{18}$ A separate analysis of all deaths by suicide in the two catchment areas was also carried out over the 9-month periods before and after the introduction of the CRT.

\section{Results}

In both CRT and control services there was reduction in admissions (both $7.7 \% ; P=0.98$ ) (Table 1) and duration of bed use (24.4\% CRT, 28.5\% control; $P=0.56$ ) (Table 2) over the two time periods (in both tables the raw figures are presented but because the population differed between the two catchment areas the rate per thousand population is also given in brackets). Separation by formal (compulsory) and informal admissions showed a greater reduction in informal admissions in the CRT compared with the control service (23\% v. 13\%), but this was offset by a greater number of compulsory admissions in the CRT service (up 31\%) compared with an increase of $7 \%$ in the control service $(P=0.743$, not significant). This finding was also demonstrated in the number of bed days, which was significantly reduced by both services, although with a greater reduction in days occupied by informally admitted 


\begin{tabular}{|c|c|c|c|}
\hline Patient status & Team & $\begin{array}{l}\text { CRT service (number } \\
\text { per } 1000 \text { population) }\end{array}$ & $\begin{array}{l}\text { Control service (number } \\
\text { per } 1000 \text { population) }\end{array}$ \\
\hline Total & $\begin{array}{l}\text { Pre-CRT } \\
\text { Post-CRT } \\
\text { Change, \% } \\
P\end{array}$ & $\begin{array}{c}222(2.69) \\
205(2.48) \\
-8 \\
n s\end{array}$ & $\begin{array}{c}598(2.79) \\
552(2.57) \\
-8 \\
n s\end{array}$ \\
\hline Compulsory & $\begin{array}{l}\text { Pre-CRT } \\
\text { Post-CRT } \\
\text { Change, \% } \\
P\end{array}$ & $\begin{array}{l}61(0.74) \\
81(0.98) \\
33 \\
n s\end{array}$ & $\begin{array}{c}162(0.76) \\
174(0.81) \\
7 \\
\text { ns }\end{array}$ \\
\hline Informal & $\begin{array}{l}\text { Pre-CRT } \\
\text { Post-CRT } \\
\text { Change, \% } \\
P\end{array}$ & $\begin{array}{c}161(1.95) \\
124(1.50) \\
-30 \\
0.012\end{array}$ & $\begin{array}{c}436(2.03) \\
378(1.76) \\
-15 \\
0.021\end{array}$ \\
\hline
\end{tabular}

ns = not significant.

patients in the CRT service (down $30 \%$ v. 9\%) and with more bed days for compulsory admissions (25\% v. $13 \%)$.

This finding was confirmed in the hierarchical model analysis: the total length of stay per patient significantly increased with the proportion of formal detentions for a patient $(P=0.0001)$, but there were no differences between the two time periods $(P=0.57)$, nor between the services $(P=0.98)$.

Three months after initial contact, 138 patients referred to CRT and 118 in the control service were randomised to have data collected. They were selected in groups at five intervals during the course of the study to have social function, service satisfaction and quality of life recorded. Unfortunately, only 20 in the CRT service (14.5\%) and 13 in the control service (11.0\%) returned completed questionnaires. These low numbers prevented proper interpretation of the data but mean service satisfaction (9.2 CRT, 9.75 control), mean social functioning (9.7 CRT, 12.3 control) and quality of life (40.6 CRT, 46.2 control) showed little difference in favour of either intervention. However, there was only one death by suicide in the CRT catchment area in the first 9 months of the study compared with nine in the control area before the introduction of the CRT, and five deaths by suicide in the CRT area in the 9 months after June 2005 (the second phase of the study) compared with six in the control area $\left(\chi^{2}=3.3, P=0.15\right)$.

\section{Discussion}

The results of this study can be summarised simply - the introduction of a crisis resolution and home treatment team in Cardiff was associated with an increase in compulsory, and a decrease in informal, admissions and bed days, but with no differences overall compared with a control service. There was also an increase in the number of deaths by suicide in the area covered by the CRT service. These conclusions have to be qualified; the evaluation only covered 9 months and this might be considered too short a time span, the ecological design involved the whole catchment area and not just the patients seen as emergencies by the two services, and the number of patients completing questionnaires for the service comparisons was too small to yield any conclusions of real value.

Nevertheless, it is hard to avoid interpreting the data in a way that does not reflect negatively on the CRT service. These suggest that the introduction of this service prevented admissions that could not be regarded as mandatory (i.e. those that were informal) but as this was

\begin{tabular}{|c|c|c|c|}
\hline Patient status & Team & $\begin{array}{l}\text { CRT service (number } \\
\text { per } 1000 \text { population) }\end{array}$ & $\begin{array}{c}\text { Control service (number } \\
\text { per } 1000 \text { population) }\end{array}$ \\
\hline Total & $\begin{array}{l}\text { Pre-CRT } \\
\text { Post-CRT } \\
\text { Change, \% } \\
P\end{array}$ & $\begin{array}{c}3478(42.0) \\
2628(31.8) \\
-24 \\
0.041\end{array}$ & $\begin{array}{c}8192(38.2) \\
5854(27.3) \\
-29 \\
0.073\end{array}$ \\
\hline Compulsory & $\begin{array}{l}\text { Pre-CRT } \\
\text { Post-CRT } \\
\text { Change, \% } \\
P\end{array}$ & $\begin{array}{c}2215(26.8) \\
2776(33.6) \\
+25 \\
0.950\end{array}$ & $\begin{array}{c}5610(26.2) \\
6365(29.7) \\
+13 \\
0.878\end{array}$ \\
\hline Informal & $\begin{array}{l}\text { Pre-CRT } \\
\text { Post-CRT } \\
\text { Change, \% } \\
P\end{array}$ & $\begin{array}{c}3918(47.4) \\
2766(33.5) \\
-42 \\
0.035\end{array}$ & $\begin{array}{c}9915(46.2) \\
8987(41.9) \\
-10 \\
0.332\end{array}$ \\
\hline
\end{tabular}


accompanied by greater numbers of compulsory admissions the gain was more than cancelled out. The reasonable assumption can be made that for many patients the prevention of admission may be followed by sufficient deterioration so that compulsory admission follows. A similar finding has been shown in a study by Keown et $a l,{ }^{19}$ who also came to a similar conclusion about the cause: 'Some of these changes may be explained by the use of home-based treatment for a group of patients who initially agree to informal treatment but gradually deteriorate and require detention under the Mental Health Act 1983. Previously they would have been in hospital and detained under section 5(2) or 5(4), but now are home treated and are detained under section 2 or 3.' It is difficult to argue that this change, if replicated generally, would be regarded as a positive one by service users, clinicians or managers unless a very short timescale is taken. In any case, the National Service Framework, ${ }^{2}$ on which the CRT initiative is based, had among its key goals 'the reduction of the numbers and length of admissions to mental hospitals and of the use of compulsion'.

We are not aware of other studies using this type of design in service evaluation in psychiatry, although it has been used in other disciplines. ${ }^{20}$ It can be defended as a more appropriate evaluation of a whole service as the introduction of any new initiative in a service has effects on the rest of the service. Staff for new developments are mainly recruited from within existing ones and so there is bound to be some disruption in other clinical teams, so although data on rare events such as suicides may not be noted in the patients directly treated, the knock-on effects from the service changes can justifiably be connected.

Our findings also identify another problem that is common to service development. The main aim of the National Health Service in introducing CRTs is to reduce bed usage and it seems clear from our data that a decision to reduce beds was made in advance of the introduction of the CRT in Cardiff and applied across all areas of the city. In the control group at the time the CRT group were working, an experienced senior nurse who knew the area well was introduced and was often available at the assessments by the on-call psychiatrist, but this was not in any way a comparable resource to the CRT. From our experience it is now common for CRT services to be introduced at the same time as a planned reduction in bed numbers and, if this is adhered to, there is bound to be a reduction in bed use. This could at least partly explain the figures of Glover et $a l^{8,9}$ without indicating any genuine effect of the CRT in reducing bed usage. Without some form of equivalent, control population claims that CRT services lead to a 'sustained reduction in in-patient admission rates ${ }^{21}$ cannot be attributed to the introduction of a CRT, as $\mathrm{Goh}^{22}$ has noted. It also has to be appreciated that there must be a finite limit to the number of bed reductions that can be achieved in a geographical area. According to Lelliott, ${ }^{23}$ the current data suggest that 'psychiatric bed numbers are close to the irreducible minimum if they have not already reached it' and, if this assertion is true, no amount of additional community resources will be able to reduce the beds further without significant risk. This point may have been reached in some areas; in Australia the state of Victoria has pioneered community care even more energetically than in the UK, but now doubts are being raised that this is not satisfying the requirements of some very needy patients. ${ }^{24}$

\section{Conclusions}

This was a controlled study but it had some deficiencies in that the services were not randomised, the control population was adjacent to that of the CRT population but differed in size and population characteristics, and which covered the whole population instead of just the patients seen by the teams as in the randomised controlled trial of Johnson et al. ${ }^{4}$ There was also no check on the fidelity of the therapeutic skills and performance in the CRT service and the two samples clearly differed in several respects which made them not strictly comparable. The clinical survey data were also very limited and possibly unrepresentative of the population. However, as data were obtained on the number of deaths by suicide in the whole area and included the period before the introduction of the CRT, it is of some concern that the numbers in the CRT area rose during the study. None of these individuals was under the care of the CRT at the time of death but the connection between their suicides and the introduction of the service deserves closer enquiry in future studies.

Although our study cannot be regarded in any way as definitive, it does cast doubts on the current approved wisdom that CRTs are an efficient and effective means of reducing both the need for, and reduction of, psychiatric bed use.

\section{Funding}

The study was funded by the Adult General Mental Health Directorate, Cardiff and Vale NHS Trust with a grant to Imperial College, London.

\section{Acknowledgements}

We thank Margaret Parry of the Patients' Resource Centre for practical assistance in organising the collection of data.

\section{About the authors}

P. Tyrer is Professor of Community Psychiatry, Imperial College London; F. Gordon is Statistical Consultant, Statistical Advisory Service, Imperial College London; S. Nourmand is Research Associate, Department of Psychological Medicine, Imperial College London; M. Lawrence works at the Pendine Centre, Cardiff; C. Curran is Consultant Psychiatrist at the Pendine Centre, Cardiff; D. Southgate works in the Psychology and Counselling Services Directorate, Whitchurch Hospital, Cardiff; B. Oruganti works at the South Cardiff Crisis Resolution and Home Treatment Team; M. Tyler works at the Cardiff and Vale NHS Trust; S. Tottle works at the Adult Mental Health Directorate, Cardiff and Vale NHS Trust; B. North and E. Kulinskaya are with the Statistical Advisory Service, Imperial College London; J. T. Kaleekal is with the South Cardiff Crisis Resolution Team; J. Morgan is Consultant Psychiatrist at the Pendine Centre, Cardiff.

\section{References}

1 Caplan G. Principles of Preventative Psychiatry. Basic Books, 1964

2 Department of Health. National Service Framework for Mental Health: Modern Standards and Service Models. Department of Health, 1999.

3 Department of Health. Crisis resolution/home treatment teams. In The Mental Health Policy Implementation Guide: 11-25. Department of Health, 2001. 
4 Johnson S, Nolan F, Pilling S, Sandor A, Hoult J, McKenzie N, et al. Randomised controlled trial of acute mental health care by a crisis resolution team: the north Islington crisis study. BMJ 2005; 331, 599602

5 Stein LI, Test MA. Alternative to mental hospital treatment. I. Conceptual model, treatment program and clinical evaluation. Arch Gen Psychiatry 1980; 37: 392-7.

6 Hoult J, Reynolds I. Schizophrenia: a comparative trial of communityoriented and hospital oriented psychiatric care. Acta Psychiatr Scand 1985; 69: 359-72.

7 Hoult J. Community care of the acutely mentally ill. Br J Psychiatry 1986; 149: $137-44$.

8 Glover G, Arts G, Babu KS. Crisis Resolution Teams and Inpatient Mental Health Care in England. Centre for Public Mental Health, University of Durham, 2005

9 Glover G, Arts G, Babu KS. Crisis resolution/home treatment teams and psychiatric admission rates in England. Br J Psychiatry 2006; 189: 441-5.

10 Johnson $\mathrm{S}$. Crisis resolution and intensive home treatment teams. Psychiatry 2003; 3, 22-5.

11 Priest RG, Fineberg N, Merson S, Kurian T. Length of stay of acute psychiatric inpatients: an exponential model. Acta Psychiatr Scand 1995, 92: $315-7$

12 Huffman MD. An improved approximate two sample Poisson test. Appl Statist 1984; 33: 224-6.

13 Welch BL. The significance of the difference between two means when the population variances are unequal. Biometrika 1937; 29: 250-362.

14 R Development Core Team. R: A Language and Environment for Statistical Computing. R Foundation for Statistical Computing, 2004
15 Rabe-Hesketh S, Skrondal A, Pickles A. GLLAMM Manual. U.C. Berkeley Division of Biostatistics Working Paper Series, Working Paper 160. University of California, 2004.

16 Larsen DL, Attkisson CC, Hargreaves WA, Nguyen TD. Assessment of client/patient satisfaction: development of a general scale. Eval Progr Planning 1979; 2: 197-207.

17 Tyrer P, Nur U, Crawford M, Karlsen S, McLean C, Rao B, et al. The Social Functioning Questionnaire: a rapid and robust measure of perceived functioning. Int J Soc Psychiatr 2005; 51: 265-75.

18 Priebe S, Huxley $\mathrm{P}$, Knight $\mathrm{S}$, Evans $\mathrm{S}$. Application and results of the Manchester Short Assessment of Quality of Life (MANSA). Int J Soc Psychiatr 1999; 45: 7-12.

19 Keown P, Tacchi MJ, Niemiec S, Hughes J. Changes to mental healthcare for working age adults: impact of a crisis team and an assertive outreach team. Psychiatr Bull 2007; 31: 288-92.

20 Rosero-Bixby L. Socioeconomic development, health interventions and mortality decline in Costa Rica. Scand J Soc Med 1991; 46 suppl: 33-42.

21 Jethwa K, Galappathie N, Hewson P. Effects of a crisis resolution and home treatment team on in-patient admissions. Psychiatr Bull 2007; 31 $170-2$.

22 Goh S-E. Crisis resolution and home treatment teams and admissions. Psychiatr Bull 2007; 31: 399.

23 Lelliott P. Acute inpatient psychiatry in England: an old problem and a new priority. Epidemiol Psichiatr Soc 2006; 15: 91-4.

24 Holmes A, Hodge M, Lenten S, Fielding J, Castle D, Velakoulis D, et al. Chronic mental illness and community treatment resistance. Australas Psychiatry 2006; 14: 272-6.

\title{
Electroconvulsive therapy: medical students' attitudes and knowledge
}

\author{
Daniel Kinnair, Sheila Dawson, Roshan Perera ${ }^{1}$
}

The Psychiatrist (2010), 34, 54-57, doi: 10.1192/pb.bp.108.023358

'Leicester General Hospital

Correspondence to Daniel Kinnair (Daniel.Kinnair@leicspart.nhs.uk)

\begin{abstract}
Aims and method With increasing numbers of students and falling numbers of individuals receiving electroconvulsive therapy (ECT) it has been difficult to timetable all students to witness ECT, and it has been suggested that this experience may be dispensed with. However, we wondered how the experience of witnessing ECT might enhance students' knowledge and, just as importantly, challenge negative perceptions of ECT. We surveyed students' attitudes and knowledge at the beginning and the end of their 8-week attachment in psychiatry.
\end{abstract}

Results There appears to be a clear benefit in terms of knowledge and positive attitudinal change for students who both witness ECT and receive a lecture on the subject.

Clinical implications Direct observation of ECT can challenge and affect attitudes in ways a lecture may not. Any changes to the provision of ECT teaching for medical students, including replacing witnessing ECT, needs to be carefully developed and assessed.

Declaration of interest None.
Electroconvulsive therapy (ECT) remains a source of controversy to the public and even among some in the medical profession. There have been studies of patients' attitudes to ECT, ${ }^{1,2}$ and several studies looking at medical students attitudes to ECT. ${ }^{3-5}$ It was felt important to ascertain medical students' attitudes and knowledge about 